\title{
Prevalence of obesity on gender base at gilgit city, Pakistan
}

\begin{abstract}
Obesity is health disorder in which accumulation of fat around the abdomen. Now a day it is health risk or life threatening concern in the developing world. Obesity is also prevalent in Gilgit, Pakistan. This cross-sectional study was conducted on 200 randomly selected volunteers from 20 to 70 aged people at four different hospitals in Gilgit, Pakistan. Those who were underweight were excluded. Interviews were conducted to determine demographic data, dietary intake, physical activity and other variables that may be associated with obesity. Self made Performa was used for the collection of data. The results revealed that obesity was most prevalent in female than males (63.5\% and 36.5\% respectively). Almost obese volunteers were between the age of 31-45years old with sedentary life style.
\end{abstract}

Keywords: obesity, prevalence, gender, physical activity, mortality
Volume 6 Issue 2 - 2017

\author{
Zubair Hussain,' Shahid Mehmood,' Babar \\ Hussain, ${ }^{2}$ Irfan Ali, ${ }^{3}$ Sonia Afzal' \\ 'Institute of Food and Nutrition, University of Sargodha, \\ Pakistan \\ ${ }^{2}$ Gilgit Baltistan Environmental Protection Agency, Pakistan \\ ${ }^{3}$ Department of Business and Administration, Karakorum \\ International University, Pakistan
}

Correspondence: Zubair Hussain, Institute of Food and Nutrition, University of Sargodha, Sargodha, Pakistan, Tel +923129728008, Email zubairaja530@gmail.com

Received: January 02, 2017 | Published: February 03, 2017

\section{Introduction}

Obesity is the negative health condition in which a person has so much fat accumulation in its body, therefore education is crucial for the consumer to improve health status. In the United Stated (US) and Canada the weight management issue due to obesity is continuously growing which results in health problem. According to reports it was observed that during 2012 adults at the age of 18 obesity was found about $27.7 \%$ in the US. The percentage of obesity was increased up to $28.9 \%$ in 2014 . There were three states in the US including Mississippi (33.5\%), West Virginia (35.7\%) and Arkansas (35.9\%) where percentage of obesity was noted higher than the national average percentage (CDCP, 2016) The prevalence of obesity in parallel in the US and Canada. According to the statistical reports of 2012 in Canada about $18.4 \%$ at the age of 18 and above 18 were found to be obese. This rate in 2014 has increased to $20.2 \%$ of Canadians age 18 and older. In the Provinces of Canada such as Newfoundland and Labrador (30.4\%), Nova Scotia (27.8\%) and New Brunswick (26.4\%) obese was recorded this was higher than the average obesity percentage (Statistics Canada, 2015).

World Health Organisation ${ }^{1}$ reported that obesity is one of the hazardous aspects for morbidity and mortality which results in coronary heart disease (CHD) ${ }^{2-4} \mathrm{CHD}$ risk factors such as non-insulin dependent diabetes mellitus, hypertension, hypertrigyceridaemia, alternations in homeostatic variables and decrease high density lipoprotein cholesterol (HDL) caused by obesity. ${ }^{2,5}$ Increased in weight in both moderate and severer overweight persons enhance the chances of heart diseases and mortality. ${ }^{1,6}$ The studies showed that many health biomarkers including blood pressure and serum lipids were improved by weight loss (up to $10 \%$ ). ${ }^{1}$ Though the health benefits of long term weight loss in relation to morbidity and premature mortality is not yet well demonstrated in studies. ${ }^{2,7}$

National Institute of Health $(\mathrm{NIH}),{ }^{8}$ recommended Body Mass
Index (BMI) for evaluating overweight, obesity and monitoring changes in body weight. According to $\mathrm{WHO}^{1}$ and $\mathrm{NIH}^{8} \mathrm{BMI}$ greater than or equal to 25 is classified as overweight whereas BMI greater than or equal to 30 is classified as overweigh. In 1995 about $63.7 \%$ adults' men and $47.0 \%$ women's were found overweight or obese in Australia. ${ }^{9}$ In the children age group of 7 to 15 years the overweight was recorded $15.0 \%$ in boys and $15.8 \%$ in girls while obese rate was found $4.5 \%$ in boys and $5.3 \%$ in girls. ${ }^{10}$ The prevalence of overweight and obesity in both adults and children has increased significantly since $1980 .^{10}$

Physical activities play an important role to reduce the risk of life threatening problems, health risk problems. ${ }^{11}$ It may help in prevention of becoming overweight and obese in childhood and adolescence. ${ }^{12}$ However, in Western society children and adolescents do not meet recommended physical activity due to which large population become overweight and obese. ${ }^{13}$ It was observed that those suffering from obesity were less physical active then other non obese, almost youngsters were among them ${ }^{14}$ they spent most of their time in sedentary pursuits, by watching television, and other electronic media using. ${ }^{13}$ It is suggested that if physical inactivity is increased then the prevalence of overweight or obese will be popular among adults and children. ${ }^{15}$ Without proper taking part in any physical activity, the childhood will be less healthy as compare to their parents. ${ }^{16}$ In the childhood obesity is the most dangerous because it causes clustering of cardiovascular disease (CVD) and atherosclerosis which developed throughout life ${ }^{17}$ whereas the obesity may be prevent through physical activity and sports in children and. The aim of this study was to check the prevalence rate of obesity at Gilgit city, Pakistan.

\section{Methodology}

The sample of the present study was taken from Gilgit, Pakistan. A total sample of 200 people was selected purposively for the study. It was divided into six difference life stages, Adolescent (13-17years), 
Young adult (18-30years), $1^{\text {st }}$ Adulthood (30-45years), $2^{\text {nd }}$ Adult hood (45-70years). Literate and illiterate people were included in this study. A self designed questionnaire was used for collection of demographic, anthropometric; all were the sources of data collection. ${ }^{18}$ District Head Quarter Hospital, Sehhat Foundation, Aga Khan Health Hospitals and City Hospital from Gilgit city were selected as study site for the research work. The cross sectional study design was adopted for research work which is utilized for estimation of the prevalence of a disease to investigate the causes of disease. Beurer 64 machine is used to check the body composition of the volunteers and Body mass index (BMI) was used to estimate the prevalence of overweight and obesity within a population, and it is calculated as weight $(\mathrm{kg}) /$ height squared $\left(\mathrm{m}^{2}\right)$. BMI was classified according to WHO criteria: Underweight, BMI $<18.50 \mathrm{~kg} / \mathrm{m}^{2}$; normal, BMI $18.50-24.99 \mathrm{~kg} /$ $\mathrm{m}^{2}$; grade 1 overweight, BMI $25.00-29.99 \mathrm{~kg} / \mathrm{m}^{2}$; grades 2 and 3 overweight, BMI $>30 \mathrm{~kg} / \mathrm{kg} / \mathrm{m}^{2}$. The data were analyzed by using SPSS version 21. Descriptive analysis such as mean frequencies and percentage were used for interpretation of the data and Figure 1-3 shows the prevalence of obesity among people.

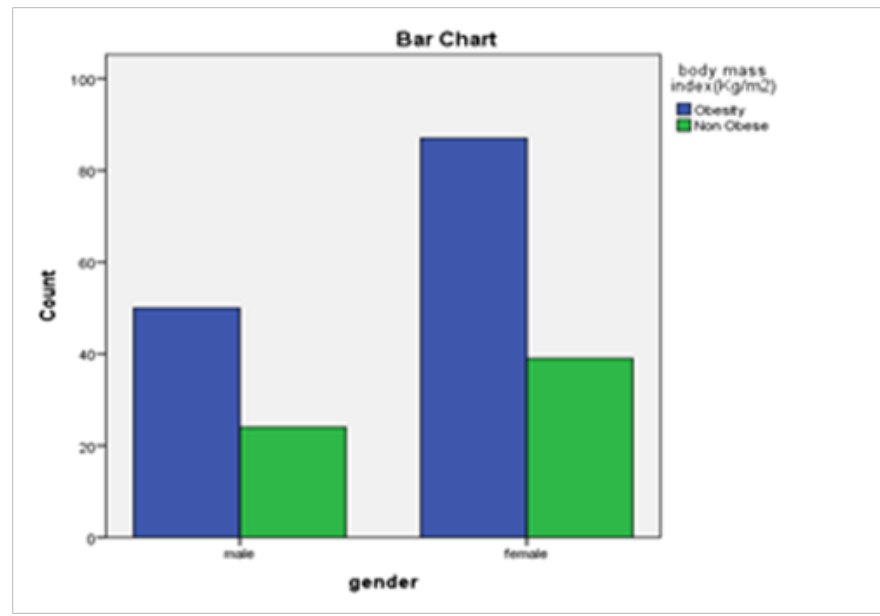

Figure I Prevalence of obesity $(B M I \geq 25)$ for men and women.

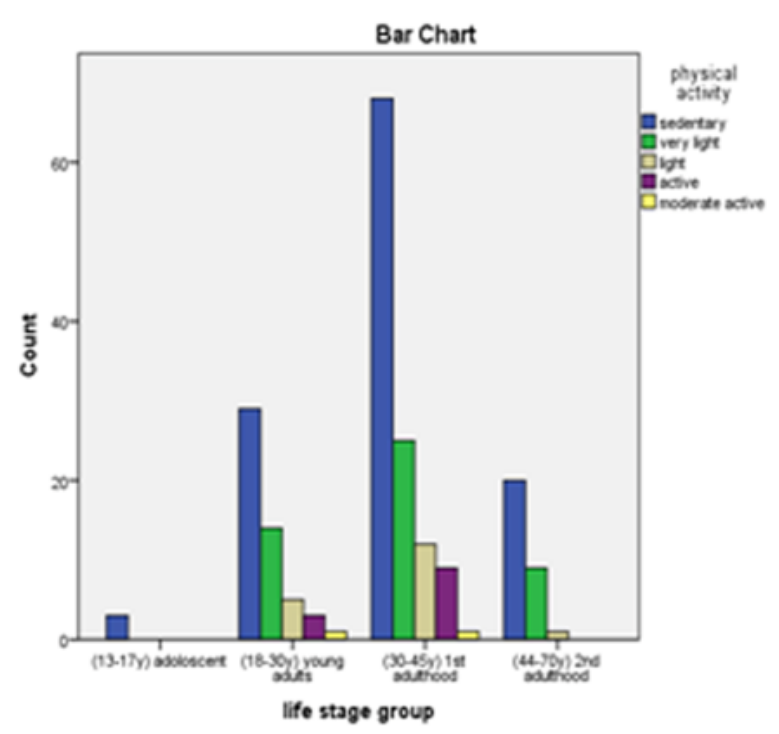

Figure 2 Prevalence of obesity (BMI 225 ) among life stage group and physical activity.

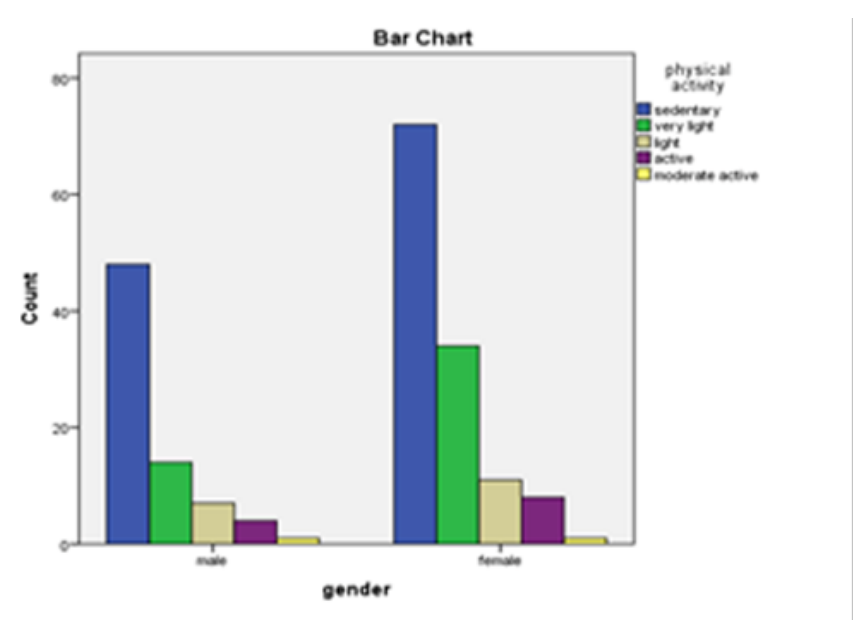

Figure 3 Prevalence of Obesity (BMI $\geq 25)$ among gender and physical activity.

\section{Results and discussion}

The Purpose of present study was to check the prevalence rate of obesity among male and female and life stage groups, at Gilgit city. Data were collected randomly from different hospitals and houses. Relationship between Gender and physiological status of volunteers is presented in Table 1 of frequency distribution. After interpretation of data, the results showed that higher frequency of obesity was among the female volunteers as compared to male. This might be due to energy imbalance and lack of physical activity. $\mathrm{NIH}^{4}$ reported that in developed countries, obesity was most prevalent in rich families particularly among females as compared to male. This result is further supported by Nanan ${ }^{19}$ investigation; prevalence of obesity was most common among women versus men in spite of age group and residence. Within the age group 25-44years, obesity occurrence was 2.4times higher in rural versus urban areas for men (9\% versus $22 \%)$ and 2.6 times higher for women (14\% versus $37 \%)$. Denis et al., ${ }^{20}$ also explored the occurrence of overweight was most popular among female then male $27 \%$ and $29 \%$ respectively, at least up to 50 years. Prevalence of obesity was more than twice as high in women as in men $(20 \%$ vs. $7 \%, \mathrm{P}<0.0001)$ and also increased with age up to 50years.

Table I Comparison of gender among obese and non obese volunteers

\begin{tabular}{lllll}
\hline \multirow{2}{*}{ Gender } & \multicolumn{3}{l}{ Physiological status } & \multirow{2}{*}{ Total } \\
\cline { 3 - 4 } & & Obesity & Non Obese & \\
\hline \multirow{2}{*}{ Male } & $f$ & 50 & 24 & 74 \\
& $\%$ & 36.5 & 38.1 & 37 \\
\multirow{2}{*}{ Female } & $f$ & 87 & 39 & 126 \\
& $\%$ & 63.5 & 61.9 & 63 \\
\multirow{2}{*}{ Total } & $f$ & 137 & 63 & 200 \\
& $\%$ & 100 & 100 & 100 \\
\hline
\end{tabular}

Association between life stage group and physical activity of random collected volunteer was shown in Table 2. The Table 2 showed that almost suffering from obesity were sedentary volunteer $56.7 \%$. Among the life stage group $1^{\text {st }}$ adulthood (31-45years) were obese. The prevalence of obesity was higher among adolescents than 
among preschool-aged children. ${ }^{15,16}$ Results revealed that both young adults and youngster had lack of physical activity they prefer indoor game then outdoor. That is why most of complications arises in human body, one of them is obesity which is life threatening, very dangerous for human body as saying in different publications. ${ }^{15,21}$ Explored that Physical activity is necessary for the proper function, growth and development of human body, either children or adolescent. ${ }^{12}$ Results revealed that physical activity may prevent from overweight and obesity in childhood and adolescence, and minimize health risk conditions.

Table 3 illustrated the association found between physical activity and gender. It was investigated that the highest frequency $(60.0 \%)$ female with sedentary physical activity were obese. Almost females have no physical activity because the females in this area were limited at their houses. Janseen et al., ${ }^{15}$ also investigated that almost young volunteers were suffering from obese which are less physical active than as compared to non obese volunteers. Caroli et al., ${ }^{14}$ also observed that those who spend more time in watching television or using other electric media also had sedentary activity were obese as compare to versus obese people. Cynthia et al., ${ }^{22}$ observed that Almost 41 million women and more than 37 million men aged 20 and over were obese in 2009-2010.

Table 2 Comparison of life stage groups and physical activity of volunteers

\begin{tabular}{|c|c|c|c|c|c|c|c|}
\hline \multirow{2}{*}{ Life stage groups } & \multicolumn{6}{|c|}{ Physical activity } & \multirow{2}{*}{ Total } \\
\hline & Se & & Very light & Light & Active & Very Active & \\
\hline \multirow{2}{*}{ Adolescent(|3-|7years) } & $f$ & 3 & 0 & 0 & 0 & 0 & 3 \\
\hline & $\%$ & 2.5 & 0 & 0 & 0 & 0 & 1.5 \\
\hline \multirow{2}{*}{ Young Adult(|8-30years) } & $f$ & 29 & 14 & 5 & 3 & I & 52 \\
\hline & $\%$ & 24.2 & 29.2 & 27.7 & 25 & 50 & 26 \\
\hline \multirow{2}{*}{ | ${ }^{\text {st }}$ Adulthood(3 |-45years) } & $f$ & 68 & 25 & 12 & 9 & 1 & 115 \\
\hline & $\%$ & 56.7 & 52.1 & 66.7 & 75 & 50 & 57.5 \\
\hline \multirow{2}{*}{$2^{\text {nd }}$ Adulthood(46-70years) } & $f$ & 20 & 9 & 1 & 0 & 0 & 30 \\
\hline & $\%$ & 16.7 & 18.8 & 5.6 & 0 & 0 & 15 \\
\hline \multirow{2}{*}{ Total } & $f$ & 120 & 48 & 18 & 12 & 2 & 200 \\
\hline & $\%$ & 100 & 100 & 100 & 100 & 100 & 100 \\
\hline
\end{tabular}

Table 3 Comparison of physical activity and gender of volunteers

\begin{tabular}{|c|c|c|c|c|c|c|c|}
\hline \multirow{2}{*}{ Gender } & & \multicolumn{5}{|c|}{ Physical activity } & \multirow{2}{*}{ Total } \\
\hline & & Sedentary & Very light & Light & Active & Very active & \\
\hline \multirow{2}{*}{ Male } & $f$ & 48 & 14 & 7 & 4 & 1 & 74 \\
\hline & $\%$ & 40 & 29.2 & 38.9 & 33.3 & 50 & 37 \\
\hline \multirow{2}{*}{ Female } & $f$ & 72 & 34 & II & 8 & 1 & 126 \\
\hline & $\%$ & 60 & 70.8 & 61.1 & 66.7 & 50 & 63 \\
\hline \multirow{2}{*}{ Total } & $f$ & 120 & 48 & 18 & 12 & 2 & 200 \\
\hline & $\%$ & 100 & 100 & 100 & 100 & 100 & 100 \\
\hline
\end{tabular}

\section{Conclusion}

There is high prevalence of obesity among the female as compare to male. Almost sedentary people were suffering from obesity either male or female. There is direct relationship between obesity and physical inactivity. This might be due to negative attitude toward outdoor physical activity.

\section{Acknowledgements}

None.

\section{Conflict of interest}

The author declares no conflict of interest.

\section{References}

1. World Health Organization (WHO). Obesity: Preventing and managing the global epidemic. Geneva, Switzerland; 1998. p. 1-268.

2. Krauss RM, Winston M, Fletcher BJ, et al. Obesity: Impact on cardiovascular disease. AHA Conference Proceedings. Circulation. 1998;98(14):1472-1476.

3. Willett WC, Manson JE, Stampfer MJ, et al. Weight, weight change, and coronary heart disease in women. JAMA. 1995;273:461-465.

4. Rimm EB, Stampfer MJ, Giovannucci E, et al. Body size and fat distribution as predictors of coronary heart disease among middle-aged and older US men. Am J Epidemiol. 1995;141(12):1117-1127. 
5. Hubert HB, Feinleib M, McNamara PM, et al. Obesity as an independent risk factor for cardiovascular disease: a 26-year follow-up of participants in the Framingham Heart Study. Circulation. 1983;67(5):968-977.

6. Calle EE, Thun MJ, Petrelli JM, et al. Body-Mass Index and mortality in a prospective cohort of US adults. N Engl J Med. 1999;341(15):10971105.

7. Institute of Medicine. Food and Nutrition Board. Committee to develop criteria for evaluating the outcomes of approaches to prevent and treat obesity. USA: Weighing the Options, National Academy Press; 1995.

8. National Institutes of Health. Clinical Guidelines on the Identification, Evaluation, and Treatment of Overweight and Obesity in adults:The Evidence Report. Obes Res. 1998;6(Suppl 2):51S-209S.

9. Australian Bureau of Statistics (ABS), Commonwealth Department of Health and Family Services. 4802.0-National Nutrition Survey: Selected Highlights Australia 1995. Canberra, Australia; 1997.

10. Magarey AM, Daniels LA, Boulton TJC. Prevalence of overweight and obesity in Australian children and adolescents: reassessment of 1985 and 1995 data against new standard international definitions. Med J Aust. 2001;174(11):561-564.

11. Centers for Disease Control and Prevention. Nutrition, Physical Activity and Obesity: Data, Trends and Maps. USA: CDC; 2016.

12. Hills AP, King NA, Armstrong TP. The contribution of physical activity and sedentary behaviours to the growth and development of children and adolescents: implications for overweight and obesity. Sports Med. 2007;37(6):533-545.

13. Hills AP, Okely AD, Baur LA. Addressing childhood obesity through increased physical activity. Nat Rev Endocrinol. 2010;6:543-549.
14. Caroli M, Argentieri L, Cardone M, et al. Role of television in childhood obesity prevention. Int J Obes Relat Metab Disord. 2004;28(Suppl 3): $104 \mathrm{~S}-108 \mathrm{~S}$.

15. Janssen I, Katzmarzyk PT, Boyce WF, et al. Overweight and obesity in Canadian adolescents and their associations with dietary habits and physical activity patterns. J Adolesc Health. 2004;35(5):360-370.

16. Must A, Tybor D. Physical Activity and Sedentary Behavior: a Review of Longitudinal Studies of Weight and Adiposity in Youth. Int J Obes. 2005 ;(29 Suppl 2):84S-96S

17. US Department of Health and Human Services. USA: National Heart, Lung, and Blood Institute; 1995.

18. Viner P, Cole T. Who Changes Body Mass between Adolescence and Adulthood? Factors Predicting Change in BMI between 16 Years and 30 Years in the 1970 British Birth Cohort. I J Obes. 2006;30(9):1368-1374.

19. Nanan DJ. The Obesity Pandemic-Implications for Pakistan. J Pak Med Assoc. 2002;52(8):342-346.

20. Dennis B, Aziz K, She L, et al. High rates of Obesity and Cardiovascular Disease risk factors in lower middle class community in Pakistan: the Metroville Health Study. JPMA. 2006;56(6):267-272.

21. Booth S, Sallis J, Ritenbaugh C, et al. Environmental and Societal Factoros Affect Food Choice and Physical Activity: Rationale, Influences and Leverage Points. Nutr Rev. 2001;59(3):21S-39S.

22. Cynthia L Ogden, Margaret D Carroll, Brian K Kit, et al. Prevalence of Obesity in the United States, 2009-2010. NCHS Data Brief. 2012;82:18. 